\title{
Cerebral gene expression in response to single or combined gestational exposure to methylmercury and selenium through the maternal diet
}

\author{
Shalini Jayashankar • Chris N. Glover • \\ Kristin I. Folven • Trond Brattelid • \\ Christer Hogstrand • Anne-Katrine Lundebye
}

Received: 22 September 2010 / Accepted: 30 December 2010 /Published online: 18 January 2011

(C) The Author(s) 2011. This article is published with open access at Springerlink.com

\begin{abstract}
Controversy remains regarding the safety of consuming certain types of seafood, particularly during pregnancy. While seafood is rich in vital nutrients, it may also be an important source of environmental contaminants such as methylmercury $(\mathrm{MeHg})$. Selenium (Se) is one essential element present in seafood, hypothesised to ameliorate $\mathrm{MeHg}$ toxicity. The aim of the present study was to ascertain the impact of $\mathrm{Se}$ on $\mathrm{MeHg}$-induced cerebral gene expression in a mammalian model. Microarray analysis was performed on brain tissue from 15-day-old mice that had been exposed to $\mathrm{MeHg}$ throughout development via the maternal diet. The results from the microarray analysis were validated using qPCR. The exposure groups included: $\mathrm{MeHg}$ alone $\left(2.6 \mathrm{mg} \mathrm{kg}^{-1}\right)$,
\end{abstract}

Electronic supplementary material The online version of this article (doi:10.1007/s10565-010-9180-4) contains

supplementary material, which is available to authorized users.

S. Jayashankar $(\bowtie) \cdot$ K. I. Folven · T. Brattelid •

C. Hogstrand - A.-K. Lundebye

National Institute of Nutrition and Seafood Research

(NIFES),

Post box 2029 Nordnes, 5817 Bergen, Norway

e-mail: sja@nifes.no

K. I. Folven

e-mail: kristinfolven@gmail.com

T. Brattelid

e-mail: tbr@nifes.no

C. Hogstrand

e-mail: christer.hogstrand@kcl.ac.uk
Se alone $\left(1.3 \mathrm{mg} \mathrm{kg}^{-1}\right)$, and $\mathrm{MeHg}+\mathrm{Se} . \mathrm{MeHg}$ was presented in a cysteinate form, and $\mathrm{Se}$ as $\mathrm{Se}-$ methionine, one of the elemental species occurring naturally in seafood. Eight genes responded to $\mathrm{Se}$ exposure alone, five were specific to $\mathrm{MeHg}$, and 63 were regulated under the concurrent exposure of $\mathrm{MeHg}$ and Se. Significantly enriched functional classes relating to the immune system and cell adhesion were identified, highlighting potential ameliorating mechanisms of $\mathrm{Se}$ on $\mathrm{MeHg}$ toxicity. Key developmental genes, such as Wnt 3 and Sparcl1, were also identified as putative ameliorative targets. This study, utilising environmentally realistic forms of toxicants, delivered through the natural route of exposure, in association with the power of transcriptomics, highlights signifi- 
cant novel information regarding putative pathways of selenium and $\mathrm{MeHg}$ interaction in the mammalian brain.

Keywords Methylmercury · Selenium · Microarray · Mice $\cdot$ Immune system $\cdot$ Cell adhesion

\section{Introduction}

Selenium (Se) is a vital nutrient, playing particularly important roles in cellular defence against reactive oxygen species (ROS), protection against carcinogenesis, and maintenance of thyroid function (Kohrle et al. 2005; Litov and Combs 1991; Bridges and Zalups 2005). However, the importance of dietary Se may also extend to an ameliorating effect on methylmercury $(\mathrm{MeHg})$ toxicity. For example, Se deficiency has been shown to potentiate adverse effects of $\mathrm{MeHg}$ toxicity in rodents (Watanabe 2002; Ralston et al. 2008), while Se supplementation has a beneficial effect on some measures of $\mathrm{MeHg}$-induced neurotoxicity (Fredriksson et al. 1993; Folven et al. 2009). Se levels in diets may also help to explain seemingly contradictory results obtained from epidemiological studies in human populations chronically exposed to low MeHg doses. Results from studies in the Faroe Islands show correlation between $\mathrm{MeHg}$ exposure and neurological developmental markers (Debes et al. 2006). This finding was in contrast to a similar study in the Seychelles that failed to identify any $\mathrm{MeHg}$ induced impairment (Myers et al. 2003, 2009; Huang et al. 2005). Faroe Islanders, by virtue of a whale meat diet, are generally exposed to $\mathrm{MeHg}$ levels that are in excess of Se levels (Julshamn et al. 1987). The Seychellois are largely ocean fish consumers and Se molar concentrations tend to greatly exceed $\mathrm{MeHg}$ concentrations in this seafood source (Robinson and Shroff 2004). This distinction could be one explanation for the different effects noted in these studies, although epidemiological evidence for an effect of $\mathrm{Se}$ on $\mathrm{MeHg}$ toxicity is currently lacking (Choi et al. 2008).

There is growing literature support that the mechanism of $\mathrm{Se}$ amelioration of $\mathrm{MeHg}$ toxicity relates to an antioxidant effect. Seppanen et al. (2004) suggested that the pro-oxidant effects of $\mathrm{MeHg}$ result from the impairment of Se-dependent antioxidant enzymes. Under this hypothesis, MeHg- induced oxidative damage is a result of loss of activity of Se-dependent antioxidant enzymes, which are critical for the ROS scavenging mechanism (Carvalho et al. 2008; Ralston and Raymond 2010). Indirect evidence favouring this hypothesis has been obtained by Beyrouty and Chan (2006) who demonstrated a similar amelioration of $\mathrm{MeHg}$ toxicity in rats treated with both $\mathrm{Se}$ and the antioxidant vitamin E. Ralston et al. (2008) suggested that selenoenzymes were a target of $\mathrm{MeHg}$ toxicity. An indirect effect was proposed, such that the formation of complexes between $\mathrm{MeHg}$ and organic Se resulted in reduced bioavailability of Se and impairment of selenoenzyme synthesis. As selenoenzymes play critical roles in anti-oxidant defence (Kohrle et al. 2005), a decrease in the levels of these enzymes due to the presence of $\mathrm{MeHg}$ would have consequences on the capacity of the body to defend itself against ROS.

In addition to its pro-oxidant properties, $\mathrm{MeHg}$ may also cause toxicity through its reactivity with cellular thiol groups (Aschner and Syversen 2005). Se has an affinity for $\mathrm{Hg}$ that is a million times greater than that of free thiols (Dyrssen and Wedborg 1991). Consequently, Se is likely to reduce the capacity of $\mathrm{MeHg}$ to inhibit enzymes that prevent and reverse oxidative damage.

These two primary modes of $\mathrm{MeHg}$ toxic action (thiol binding and oxidative stress) are non-specific and thus cause the characteristic wide-ranging impacts of $\mathrm{MeHg}$ toxicity including apoptosis, cytoskeletal abnormalities, altered neurotransmitter regulation, and impaired cell migration (Aschner and Syversen 2005). Effects of Se can, however, be specific (e.g. Reed et al. 2008; Folven et al. 2009), suggesting a component of Se amelioration could be due to actions on specific biological pathways. This may be in addition to a generalised effect on $\mathrm{MeHg}$ bioreactivity. The pluripotency of $\mathrm{MeHg}$ toxicity means that the identification of specific mechanisms of $\mathrm{Se}$ amelioration requires techniques that are capable of rapidly screening a large number of possible targets and pathways. Microarray analysis, which simultaneously assesses whole tissue changes in gene expression, is a powerful tool for identifying pathways through which Se might mediate its actions. It has previously been successfully used to identify putative markers of $\mathrm{MeHg}$ toxicity (Glover et al. 2009), and has great utility for identifying cellular pathways and structures through which Se may modify $\mathrm{MeHg}$ effects. 
The present study aimed to evaluate the potential of Se to ameliorate $\mathrm{MeHg}$ toxicity in the gestationally exposed, developing mouse brain by use of microarray and quantitative reverse transcription-polymerase chain reaction (qRT-PCR) technology. Dosing occurred via the natural route of exposure (the diet) using forms of Se (Se-methionine; Cabanero et al. 2004) and $\mathrm{MeHg}$ (MeHg-cysteinate; Harris et al. 2003) that occur naturally in seafood. Inorganic Se is more commonly used in laboratory studies but has been shown in some investigations to be less bioavailable than Se-methionine (Ørnsrud and Lorentzen 2002; Fox et al. 2004) which may have consequences for its capacity to ameliorate $\mathrm{MeHg}$ toxicity. Similarly, recent evidence has shown significant differences between the toxic effects induced by $\mathrm{MeHgCl}$ (the laboratory salt) and $\mathrm{MeHgCys}$ in gestationally exposed mice (Glover et al. 2009). The experimental approach used in this study resembled a natural exposure regime and identified potentially important targets of interactions between $\mathrm{Se}$ and $\mathrm{MeHg}$ in the brains of developing mice.

\section{Materials and methods}

\section{Animal husbandry}

The animals used for this experiment were previously subjected to neurobehavioural analyses. Detailed information regarding animal husbandry and experimental diets can be found in Folven et al. (2009). A total of 36 female balb/c mice (Taconic Inc., Denmark) were used in the experiment. Initially mice were housed three per cage, with cages randomly distributed within racks to minimise effects of any variations in housing conditions. A $12 \mathrm{~h}$ light and dark cycle was maintained during the course of the trial. The experimental protocol was approved by the Norwegian Animal Research Authority, and all procedures described were performed in accordance with their recommendations.

Experimental diets and dietary exposure regime

Four different dietary treatments were designed. The treatment groups included: Control; $\mathrm{MeHg}$ alone $\left(\sim 2.6 \mathrm{mg} \mathrm{kg}{ }^{-1}\right)$, Se $\left(\sim 1.3 \mathrm{mg} \mathrm{kg}{ }^{-1}\right), \mathrm{MeHg}$ $\left(\sim 2.6 \mathrm{mg} \mathrm{kg}^{-1}\right)+\mathrm{Se}\left(\sim 1.3 \mathrm{mg} \mathrm{kg}^{-1}\right.$; Table 1$)$. MeHg was presented as a cysteinate salt, and $\mathrm{Se}$ as $\mathrm{Se}-$
Table $1 \mathrm{Se}$ and total $\mathrm{Hg}$ concentrations ( $\mathrm{mg} \mathrm{kg}^{-1}$ and $\mu \mathrm{mol} \mathrm{kg}{ }^{-1}$ ) in the experimental diets

\begin{tabular}{lccc}
\hline $\begin{array}{l}\text { Experimental } \\
\text { diet }\end{array}$ & $N$ & $\begin{array}{c}\mathrm{Se} \mathrm{mg} \mathrm{kg}^{-1} \\
\left(\mu \mathrm{mol} \mathrm{kg}^{-1}\right)\end{array}$ & $\begin{array}{c}\mathrm{Hg}\left(\mathrm{mg} \mathrm{kg}^{-1}\right) \\
\left.(\mu \mathrm{mol} \mathrm{kg})^{-1}\right)\end{array}$ \\
\hline Control & 4 & $\begin{array}{c}0.24 \pm 0.1 \\
(3 \pm 1.3)\end{array}$ & $\begin{array}{c}<0.03^{\mathrm{a}} \\
\left(<0.15^{\mathrm{a}}\right)\end{array}$ \\
$\mathrm{MeHg}$ & 4 & $\begin{array}{c}0.22 \pm 0.04 \\
(2.8 \pm 0.5)\end{array}$ & $\begin{array}{c}2.6 \pm 0.5 \\
(12.9 \pm 2.5)\end{array}$ \\
$\mathrm{Se}$ & 4 & $\begin{array}{c}1.3 \pm 0.4 \\
(16.5 \pm 5.1)\end{array}$ & $<0.03^{\mathrm{a}}$ \\
& & $\left.1.3 \pm 0.15^{\mathrm{a}}\right)$ \\
$\mathrm{MeHg}+\mathrm{Se}$ & 4 & $(16.5 \pm 5.06)$ & $2.6 \pm 0.8$ \\
& & & $(12.9 \pm 4)$ \\
\hline
\end{tabular}

Values are given as the mean $\pm \mathrm{SD}$

${ }^{a}$ Represents the limit of quantification $(<0.03 \mathrm{mg} \mathrm{Hg} \mathrm{kg} \mathrm{dry}$ weight $^{-1}$ ). The above data is adapted from Folven et al. (2009)

methionine (SeMet). Diets were casein-based and presented to mice in a powdered form (see Folven et al. 2009 for more details).

Each treatment group was randomly assigned nine female mice. The mice were acclimated for a period of 1 week on the control diet. Following acclimation, the mice received experimental diets ad libitum for 3 weeks prior to breeding, during breeding, gestation and for 2 weeks post-partum (a total of 8 weeks of exposure for dams at experiment termination). The amount of feed consumed was approximately $3.5 \mathrm{~g}$ per mouse prior to pregnancy, $6 \mathrm{~g}$ per mouse during gestation and $10 \mathrm{~g}$ per mouse during lactation. Consumption rates per cage were monitored (see Folven et al. 2009). The female mice were separated into individual cages on gestation day 16.

\section{Tissue sampling}

Mice pups were sacrificed on postnatal day 15 . The corresponding dams were also sacrificed at this time. Animals were anaesthetised using a medetomidine/ ketamine mixture (Domitor ${ }^{\circledR}$, Orion Corp., Turku, Finland/Ketalar ${ }^{\circledR}$, Pfizer Inc., New York, USA) followed by cervical dislocation. Brain and liver tissues were dissected out, weighed and snap frozen in liquid nitrogen. The samples were stored at $-80^{\circ} \mathrm{C}$ for gene expression profiling and chemical analysis. For the latter, tissue and feed samples were subjected to microwave digestion in concentrated nitric acid and hydrogen peroxide, before being analysed for total $\mathrm{Hg}$ and Se by inductively coupled plasma mass spectrometry (Agilent quadrupole $7500 \mathrm{C}$, Yokogawa 
Analytical System Inc., Tokyo, Japan). Rhodium was used as the internal standard, and a certified reference material (Dogfish muscle, DORM-2, Ottawa, Canada) was also included in the analysis to assess accuracy (Julshamn et al. 2007).

\section{RNA isolation}

Frozen whole brain samples were homogenised using a bead grinding protocol $(6,000 \mathrm{rpm}, 3 \times 10 \mathrm{~s}$; Precellys 24, Bertin Technologies). Total RNA was isolated using Trizol reagent (Invitrogen) and further purified on columns specific for lipid-rich tissues (RNeasy Lipid Tissue Mini Kit; Qiagen). RNA concentration was measured spectrophotometrically (Nanodrop ${ }^{\circledR}$ ND1000; NanoDrop Technologies, Wilmington, DE, USA). The integrity of the RNA samples was monitored using microcapillary electrophoresis (Agilent 2100 Bioanalyser; Agilent Technologies, Palo Alto, CA, USA).

\section{Microarray}

RNA samples from pup brains were subjected to microarray analysis (control, $n=4 ; \mathrm{MeHg}=4 ; \mathrm{MeHg}+$ high level Se, $n=4$; high Se, $n=4$ ). The reference pool was made using aliquots of all the RNA samples that were subjected to microarray analysis. Aminoallyl complementary DNA (cDNA) was synthesised using Superscript $^{\mathrm{TM}}$ Indirect cDNA Labelling System following the manufacturer's protocol (Invitrogen). Fluorescent labelling was performed using $\mathrm{Cy} 3$ (reference) and Cy5 (sample) dyes (Amersham). A mixture of labelled reference and the sample cDNA was applied to microarrays spotted with 35,852 65-mer oligonucleotide probes representing approximately 25,000 genes and approximately 38,000 gene transcripts (mouse OpArray, 4.0, Operon, Huntsville, AL, USA) according to the manufacturer's protocol.

Microarray slides were immersed in pre-warmed prehybridisation solution $(5 \times \mathrm{SSC}, 0.1 \% \mathrm{SDS}, 0.1 \%$ BSA) and placed in an oven at $42^{\circ} \mathrm{C}$ for $45-60 \mathrm{~min}$. Thereafter, the prehybridised slides were transferred to $0.1 \times \mathrm{SSC}$ and incubated for $30 \mathrm{~s}$ at room temperature. Hybridisation involved the addition of $25 \mu \mathrm{l}$ of fresh hybridisation solution (25\% formamide, $5 \times \mathrm{SSC}, 0.1 \% \mathrm{SDS})$ to appropriate amounts of reference and treatment samples ( $\sim 50$ pmol each) which were dried in a vacuum microcentrifuge (Eppendorf), then denatured at $95^{\circ} \mathrm{C}$ for $5 \mathrm{~min}$. The samples were applied to the prehybridised slides in humidified hybridisation chambers and incubated at $42^{\circ} \mathrm{C}$ for $16-20 \mathrm{~h}$.

Following hybridisation, the slides were washed as follows: wash solution 1 ( $2 \times \mathrm{SSC}, 0.1 \%$ SDS $)$ prewarmed at $42^{\circ} \mathrm{C}$ for $5 \mathrm{~min}$ twice; wash solution $2(0.1 \times$ $\mathrm{SSC}, 0.1 \% \mathrm{SDS}$ ) for $5 \mathrm{~min}$ twice, room temperature; wash solution $3(0.1 \times \mathrm{SSC})$ four times, room temperature; wash solution $4(0.01 \times \mathrm{SSC}) 10 \mathrm{~s}$, room temperature. Once slides were dried, they were scanned in Perkin Elmer Scanner using Scan Array Express. The photomultiplier tube gain was set between $60 \%$ and $80 \%$.

Scanned images were subjected to a normalisation procedure (LOWESS) using BlueFuse (BlueGnome). The resulting post-quantified data was imported into GeneSpring GX 7.3 for further normalisation and statistical analysis.

\section{Analysis}

The data was first normalised "per spot and per chip" dependent on the intensity. Each gene was normalised to specific samples and median. Each chip was normalised to the 50th percentile. The resulting data was first filtered by excluding genes with "absent" flags in more than eight out of the 16 samples and above a signal intensity of 300 . A fold change filter on the resulting list was applied to include genes with relative expression levels 1.5 -fold or more from control in at least one out of the three comparisons. The resulting list of genes was subjected to statistical tests. We followed a dual approach where we presented gene lists using multiple test correction (MTC; core analysis) and utilised gene lists produced without MTC for functional annotation enrichment analysis. This approach allowed reduction of falsepositives in the core analysis gene lists and also enabled the presentation of expression of genes carrying statistically over-represented functional annotations.

For the core analysis, the fold change values of genes were $\log _{2}$ transformed and subjected to a parametric ANOVA without assuming equal variances. Benjamini and Hochberg multiple comparison correction was performed with a false discovery rate (FDR) of 5\%. Gene lists with complete annotations are given in the Supplementary data. Heat maps of the resulting gene lists were created using MultiExperimentViewer (Saeed et al. 2003) and hierarchical clustering on 
treatments was performed to analyse how different experimental groups related to each other in terms of similarity of gene expression patterns. We also attempted to cluster on a per sample basis; however, microarrays were unable to completely discriminate between individuals assigned to different treatment groups.

For identifying functional clusters of genes impacted, we used a two-tiered approach in which a primary gene list was produced from non-stringent statistics (the fold change values of genes were $\log _{2}$ transformed and each treatment was tested pairwise against control using Welch $t$ test $(p<0.05))$, but the subsequent enrichment analyses filtered out false positives. The rationale for this approach was that a random gene list does not contain overrepresentation of any particular gene category and that enrichment in functional annotation is caused by treatment. Therefore, whilst an uncorrected gene list will contain a relatively large proportion of false positives, the genes from this list carrying statistically enriched annotations are much more likely to be truly regulated. The final lists of significant genes under each treatment were uploaded into the Database for Annotation, Visualisation, and Integrated Discovery (DAVID; Dennis et al. 2003) and a functional annotation enrichment analysis was performed. The DAVID functional annotation tool uses a one-tailed Fisher's exact test in order to calculate the enrichment of specific annotations within a gene list. We also performed functional annotation enrichment analysis on the gene list resulting from stringent statistics (FDR $<0.05)$. This approach did not yield significant new information, owing to the small number of genes that passed the analysis $(<100)$. These numbers were insufficient to allow mapping of gene groups to cellular pathways.

Quantitative real-time PCR

RNA isolated from brain tissue was subjected to reverse transcription polymerase chain reaction (RT PCR; control, $n=4 ; \mathrm{MeHg}=4$; $\mathrm{MeHg}+$ high level $\mathrm{Se}, n=4$; high Se, $n=4)$. The reverse transcription procedure included the following reagents: $10 \times$ Taqman RT buffer; $25 \mathrm{mM} \mathrm{MgCl} 2 ; 10 \mathrm{mM}$ deoxyNTPs; Oligod(T) 16 ; RNase Inhibitor; Multiscribe reverse transcriptase (Applied Biosystems, Foster City, CA, USA). The reaction was performed at $48^{\circ} \mathrm{C}$ for 60 min on a GeneAmp PCR 9700 machine (Applied Biosystems, Foster City, CA, USA).
Following the synthesis of cDNA, real-time PCR was performed using a LightCycler ${ }^{\circledR} 480$ Real-Time PCR System (Roche Applied Sciences, Basel, Switzerland). The reaction mixture contained cDNA, $2 \mu \mathrm{l}$; LightCycler $^{\circledR} 480$ SYBR Green master mix kit, Roche Applied Sciences, $10 \mu \mathrm{l}$; primer assay, QuantiTech, Qiagen, $2 \mu \mathrm{l}$; and deionised water, $6 \mu \mathrm{l}$. The real-time reaction utilised the following steps: activation for $5 \mathrm{~min}$; heating to $95^{\circ} \mathrm{C}$ for $10 \mathrm{~min} ; 45$ cycles of $15 \mathrm{~s}$ denaturation at $95^{\circ} \mathrm{C} ; 60 \mathrm{~s}$ annealing at $55^{\circ} \mathrm{C}$ (set according to the primer specifications); $30 \mathrm{~s}$ of elongation at $72^{\circ} \mathrm{C}$.

\section{Analysis}

The raw data was subjected to relative quantification using the efficiency values calculated by the second derivative method on the LightCycler ${ }^{\circledR} 480$ Real-Time PCR System (Roche Applied Sciences, Basel, Switzerland). The standard curve was plotted using twofold dilutions of the reference pool (pool of target samples). Six reference genes (cytochrome $\mathrm{C} 1$, cytoplasmic $\beta$ actin, ubiquitin $C$, glyceraldehyde-3-phosphate dehydrogenase, ribosomal L 13 A, elongation factor 4) were examined by GeNorm (Vandesompele et al. 2002) and the gene with the smallest cross-sample variability (elongation factor $4 ; M=0.174$ ) was selected. For comparing results from the two methods, microarray and qualitative polymerase chain reaction (qPCR), we analysed a total of six replicates which included data from brain samples included in the array analysis, plus an additional two brains that were not subjected to microarray. Data for the qPCR analysis is presented with both the specific samples used for array and the total number of samples analysed.

Statistical analysis on the qPCR data was performed using GraphPad Prism 5.0 software (GraphPad software, Inc.). A non-parametric Mann-Whitney test was used to determine the statistical differences among the treatments. A statistical difference of $P<0.05$ was deemed significant.

\section{Results}

Tissue accumulation

The measured concentrations of $\mathrm{Hg}$ and $\mathrm{Se}$ in the diets are provided in Table 1 . The average $\mathrm{Hg}$ concentration in the diets with $\mathrm{MeHg}$ was $2.6 \mathrm{mg} \mathrm{kg}^{-1}$ with no 
significant differences between MeHg-containing diets. The estimated $\mathrm{MeHg}$ dose received by the $\mathrm{MeHg}$ exposed dams during the course of the trial was $\sim 500 \mu \mathrm{g} \mathrm{MeHg} \mathrm{kg} \mathrm{body} \mathrm{weight}{ }^{-1}$ day $^{-1}$ (Folven et al. 2009). In the $\mathrm{MeHg}$ diet the molar ratio of $\mathrm{MeHg}$ to Se was 4.6:1, compared to $0.78: 1$ in the $\mathrm{MeHg}+\mathrm{Se}$ diet.

Tissue accumulation levels of total $\mathrm{Hg}$ and $\mathrm{Se}$ are given in Table 2. Se concentrations in the Se-supplemented pup brains and livers were significantly higher than in the control. There were no significant differences in brain Se concentrations between the $\mathrm{Se}$ alone and the $\mathrm{Se}+\mathrm{MeHg}$ groups; however, there was a significant difference between the $\mathrm{Se}$ levels in the livers of these groups. $\mathrm{Hg}$ concentrations in brains and livers were significantly higher in the Se supplemented group relative to the control (Folven et al. 2009).

\section{Reproductive success and adult mortality}

Of the females mated, $63 \%$ produced litters with an average litter size of three pups per litter. No adult mortality was observed in any of the exposure groups. Further details regarding reproductive parameters may be found in Folven et al. (2009).

\section{Microarray}

A total of 28,549 transcripts were scored as "present" on the arrays based on flags (marginal or present) and a hybridisation signal intensity in excess of 300 . Transcripts that exhibited expression greater than 1.5 -fold different from the control were carried forward for statistical analysis. Statistical analysis on the list of genes from the filtering resulted in a total of 76 genes among the three treatment groups, which showed a significant $(\mathrm{FDR}<0.05)$ differential regulation relative to the control. The degree of differential regulation was always less than fourfold (see Supplementary data). Of these genes, eight responded to Se exposure alone, five were specific to $\mathrm{MeHg}$, and 63 were regulated under $\mathrm{MeHg}+\mathrm{Se}$ exposure. Figure 1 represents the change in gene expression (relative to the control) of genes belonging to the different treatments. The genes belonging to each treatment were subjected to hierarchical clustering which provided information regarding the relationships between the genes and exposure groups.

Functional annotation enrichment analysis was performed on the non stringent list of genes, that is the gene list obtained before the application of MTC (those with at least a 1.5-fold change in expression

Table 2 Concentrations ( $\mathrm{mg} \mathrm{kg}^{-1}$ and $\mu \mathrm{mol} \mathrm{kg}{ }^{-1}$ ) of total $\mathrm{Se}$ and $\mathrm{Hg}$ in brain and liver of mice offspring gestationally exposed to $\mathrm{MeHg}$ and/or Se

\begin{tabular}{|c|c|c|c|c|c|}
\hline \multirow[b]{2}{*}{ Treatment } & \multirow[b]{2}{*}{$N$} & \multicolumn{2}{|c|}{ Brain } & \multicolumn{2}{|c|}{ Liver } \\
\hline & & $\begin{array}{l}\text { Se mg kg }{ }^{-1} \\
\left(\mu \mathrm{mol} \mathrm{kg}{ }^{-1}\right)\end{array}$ & $\begin{array}{l}\mathrm{Hg} \mathrm{mg} \mathrm{kg} \\
\left(\mu \mathrm{mol} \mathrm{kg}{ }^{-1}\right)\end{array}$ & $\begin{array}{l}\text { Se mg kg } \\
\left(\mu \mathrm{mol} \mathrm{kg}{ }^{-1}\right)\end{array}$ & $\begin{array}{l}\mathrm{Hg} \mathrm{mg} \mathrm{kg} \\
\left(\mu \mathrm{mol} \mathrm{kg}{ }^{-1}\right)\end{array}$ \\
\hline \multirow[t]{2}{*}{ Control } & \multirow[t]{2}{*}{4} & $0.11 \pm 0.02$ & $<0.03^{\mathrm{b}}$ & $0.41 \pm 0.05$ & $<0.03^{\mathrm{b}}$ \\
\hline & & $(1.4 \pm 0.25)$ & $<0.15^{\mathrm{a}}$ & $5.2 \pm 0.24$ & $<0.15^{\mathrm{a}}$ \\
\hline \multirow[t]{2}{*}{$\mathrm{Se}$} & \multirow[t]{2}{*}{4} & $0.29 \pm 0.03^{*}$ & $<0.03^{\mathrm{b}}$ & $1.0 \pm 0.1^{*}$ & $<0.03^{\mathrm{b}}$ \\
\hline & & $\left(3.7+0.4^{*}\right)$ & $<0.15^{\mathrm{a}}$ & $12.6 \pm 1.3^{*}$ & $<0.15^{\mathrm{a}}$ \\
\hline \multirow[t]{2}{*}{$\mathrm{MeHg}$} & \multirow[t]{2}{*}{2} & $<0.1^{\mathrm{a}}$ & $0.31 \pm 0.04$ & $0.37 \pm 0.02$ & $0.30 \pm 0.2$ \\
\hline & & $(<1.3)^{\mathrm{a}}$ & $1.54+0.2$ & $4.7 \pm 0.25$ & $1.5 \pm 1$ \\
\hline \multirow[t]{2}{*}{$\mathrm{MeHg}+\mathrm{Se}$} & \multirow[t]{2}{*}{4} & $0.35 \pm 0.05^{*}$ & $0.21 \pm 0.2^{*}$ & $1.3 \pm 0.2^{*}, * *$ & $0.29 \pm 0.09^{*}$ \\
\hline & & $(4.4+0.6)^{*}$ & $1.04+1^{*}$ & $16.4 \pm 2.5^{*}, * *$ & $1.4 \pm 0.4^{*}$ \\
\hline
\end{tabular}

Values are given as the mean $+\mathrm{SD}$

The above data is adapted from Folven et al. (2009)

${ }^{a}$ Represent the limits of quantification for total Se $\left(0.1 \mathrm{mg}\right.$ Se $\mathrm{kg}$ dry weight $\left.{ }^{-1}\right)$

${ }^{\mathrm{b}}$ Represent the limits of quantification for total $\mathrm{Hg}\left(0.03 \mathrm{mg} \mathrm{Hg} \mathrm{kg} \mathrm{dry} \mathrm{weight}{ }^{-1}\right)$

${ }^{*} p<0.05$, indicates statistical significance relative to the control

${ }^{* *} p<0.05$ indicates statistical significance relative to the corresponding Se-supplemented treatment 


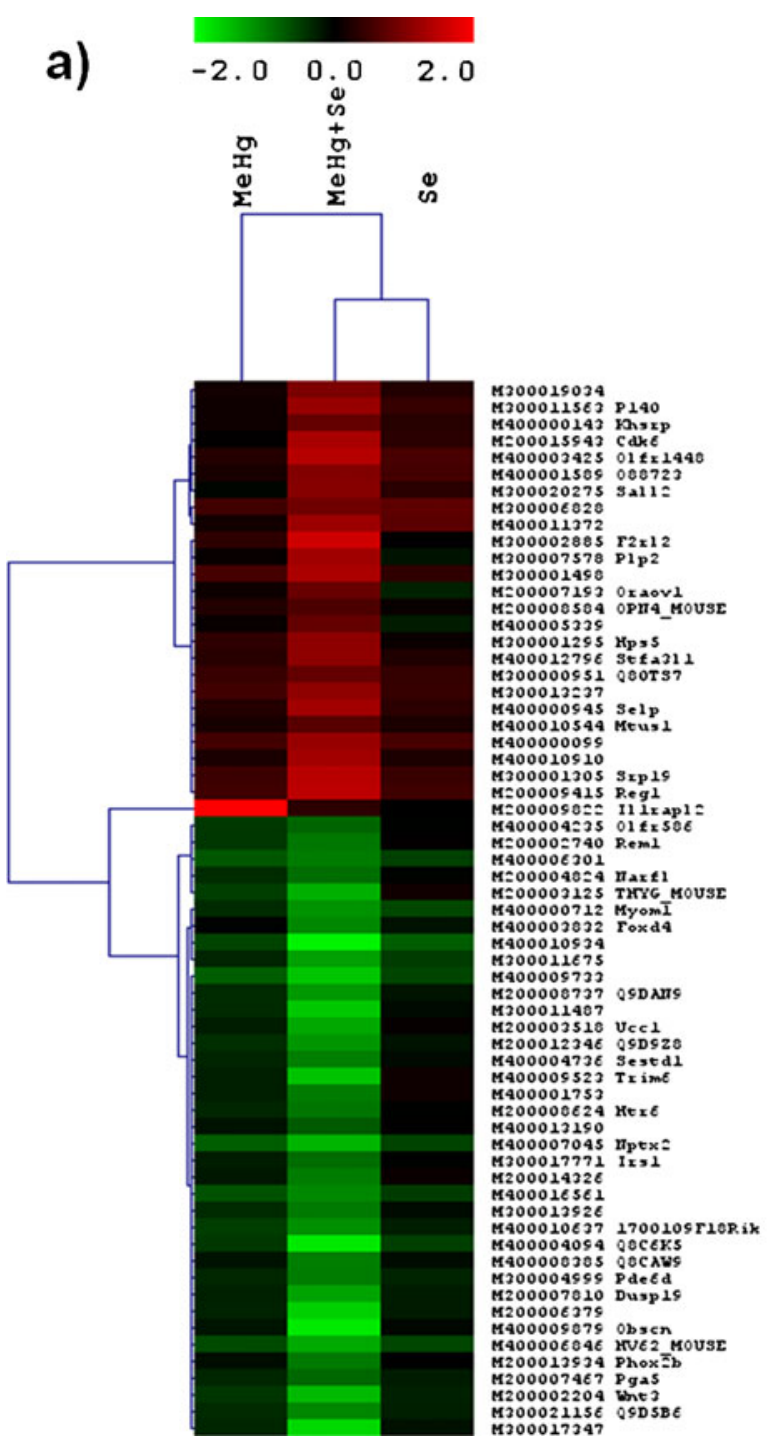

Fig. 1 Hierarchical clustering analysis of genes in murine pup whole brain following exposure to dietary $\mathrm{MeHg}$ and/or Se. These heat maps were generated using MultiExperimentViewer (Saeed et al. 2003) with hierarchical clustering performed via Pearson correlation using fold change values of differentially expressed genes. Rows represent genes and columns represent

relative to the control, and which passed the filtering and normalisation processes) using DAVID (Dennis et al. 2003). The non-stringent list of genes contained a total of 746 genes were regulated exclusively by the combined exposure of $\mathrm{MeHg}+\mathrm{Se}$, while 118 were specific to $\mathrm{MeHg}$ exposure. Seventy-eight genes were specific to "Se" treatment, with the remaining genes exhibiting change in response to treatment combinations. A number of functional classes were identified as
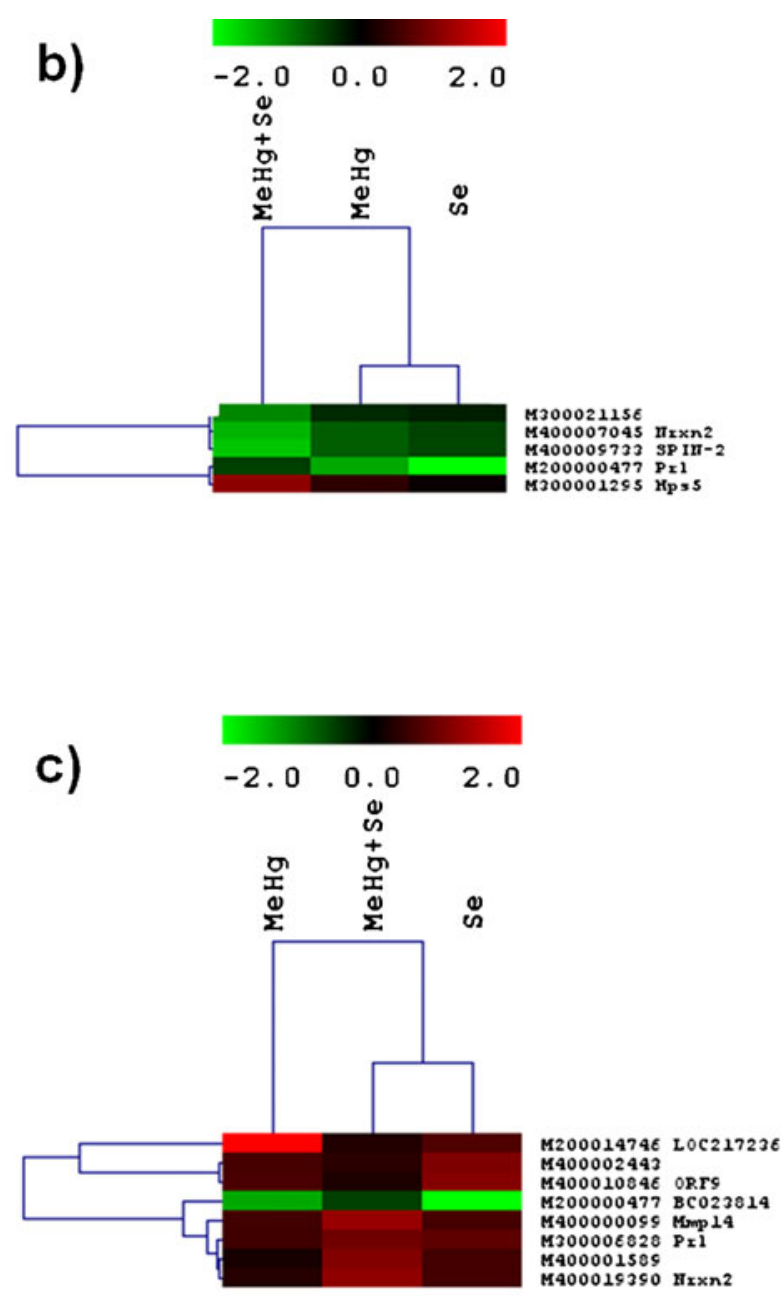

samples. Red and green blocks respectively represent high and low expression relative to the reference RNA, while black blocks indicate equal expression. Treatments are as follows: a $\mathrm{MeHg}+\mathrm{Se}(n=4), \mathbf{b} \mathrm{MeHg}(n=4)$, c Se $(n=4)$. For more details on each gene, refer to the supplementary data

significantly enriched following gestational exposure to the experimental treatments (Table 3). Distinct clusters of genes related to "morphogenesis", "immune system", "response to stress", "cytoskeleton", and "cell proliferation" were enriched under $\mathrm{MeHg}$ exposure, while those related to "positive regulation", "immune system", "metabolic process", "response to stress", "catabolic process", "protein metabolism", and "cytoplasm" were significantly enriched following Se 
Table 3 Over-represented functional groups among genes regulated by $\mathrm{MeHgCys}$, Se and $\mathrm{MeHgCys}+\mathrm{Se}$

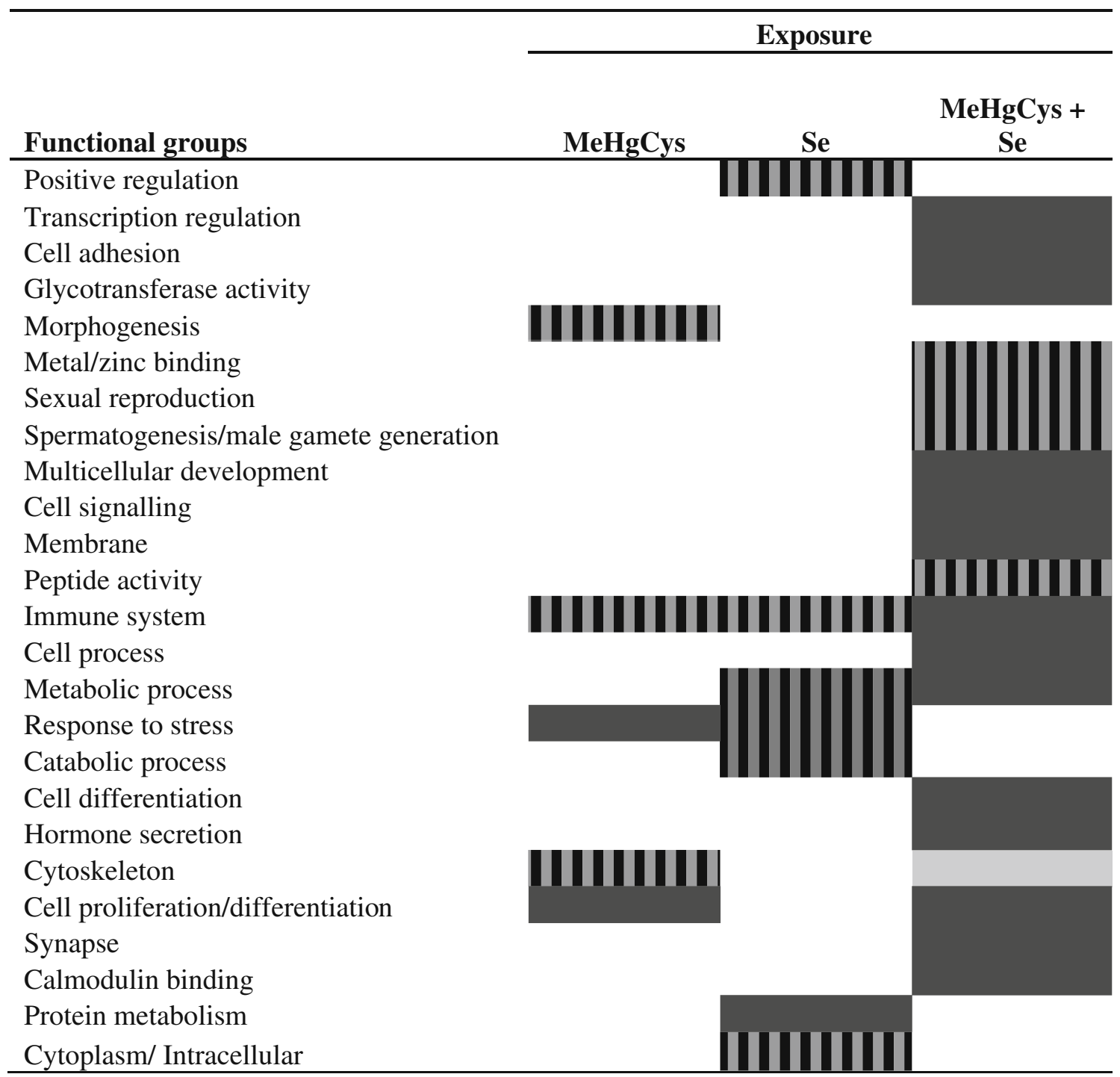

The analysis was performed using the Database for Annotation, Visualisation and Integrated Discovery (DAVID, Dennis et al. 2003). See text for more details. Shading of the entry indicates the significance value of the most annotation group within the cluster (dark grey, $p<0.05$; grey with vertical hatching, $p<0.1$; light grey, $p>0.1$ )

exposure. The combined exposure to $\mathrm{MeHg}$ and $\mathrm{Se}$ caused significant changes in gene expression that clustered in groups related to "transcription regulation", "cell adhesion", "glycotransferase activity", "metal/zinc binding", "sexual reproduction", "spermatogenesis/male gamete generation", "multicellular development", "cell signalling", "membrane", "peptide activity", "immune system", "cell process", "metabolic process", "cell differentiation", "hormone secretion", "cytoskeleton", "cell proliferation/differentiation", "synapse", and "calmodulin binding". Functional classes related to "stress response" were common to $\mathrm{Se}$ and $\mathrm{MeHg}$ exposure groups, while those related to "metabolic process" were enriched among those genes differentially expressed in both $\mathrm{Se}$ and $\mathrm{MeHg}+\mathrm{Se}$ exposure groups. "Immune system" was a functional cluster common to all three treatments.

Figure 2 represents the most significant functional clusters affected by exposure to $\mathrm{MeHg}$ and/or Se, and their changes in expression relative to the control. The 


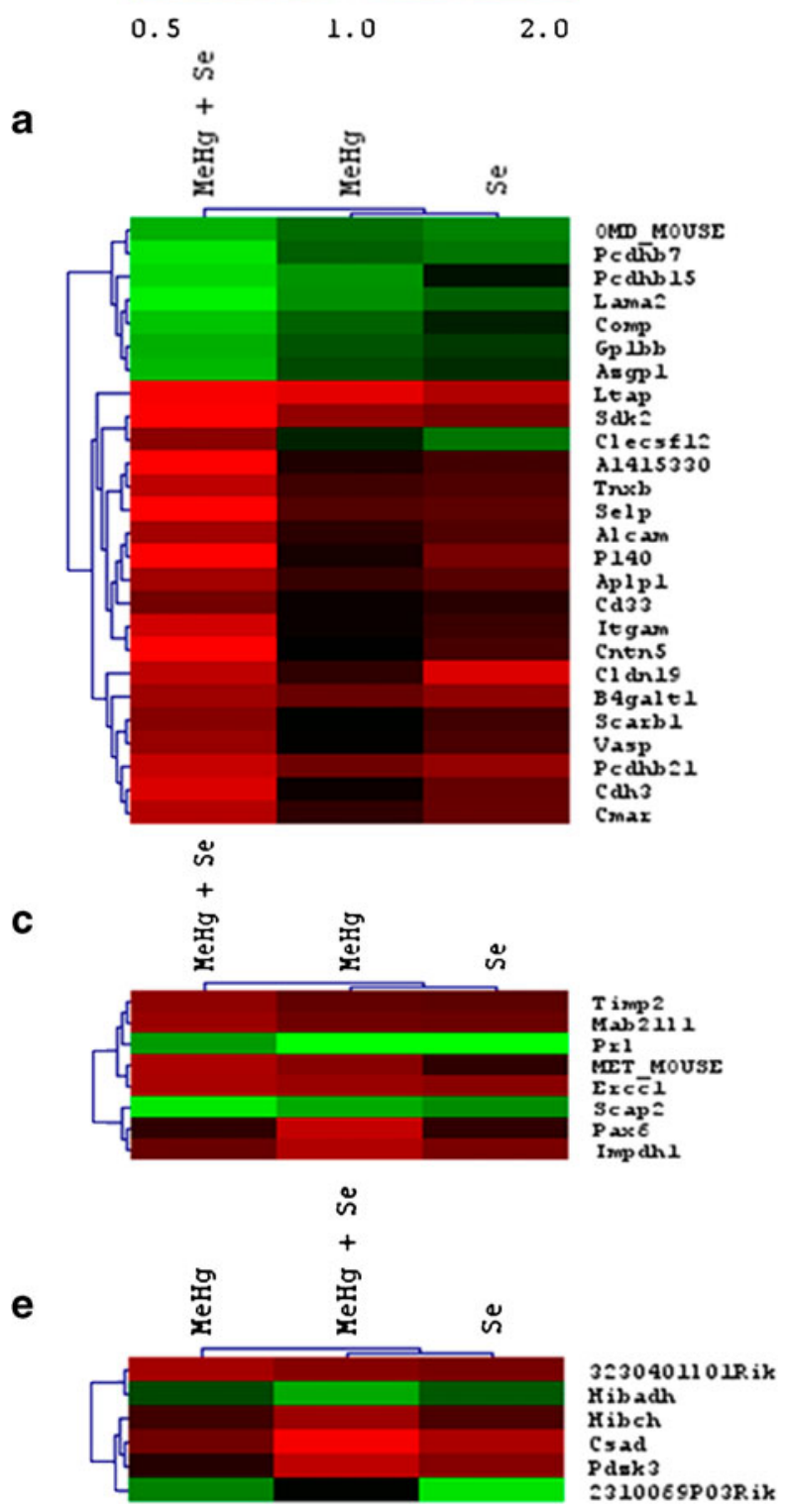

Fig. 2 Hierarchical clustering analysis of genes present in enriched functional clusters following $\mathrm{MeHg}$ and/or Se exposure. These functional clusters correspond to the results from functional annotation enrichment analysis derived from the Database for Annotation, Visualisation and Integrated Discovery (DAVID, Dennis et al. 2003). Heat maps were generated using MultiExperimentViewer (Saeed et al. 2003), with hierarchical clustering performed via Pearson correlation using $\log$ transformed expression ratios of differentially expressed genes. Rows represent genes and columns represent samples.

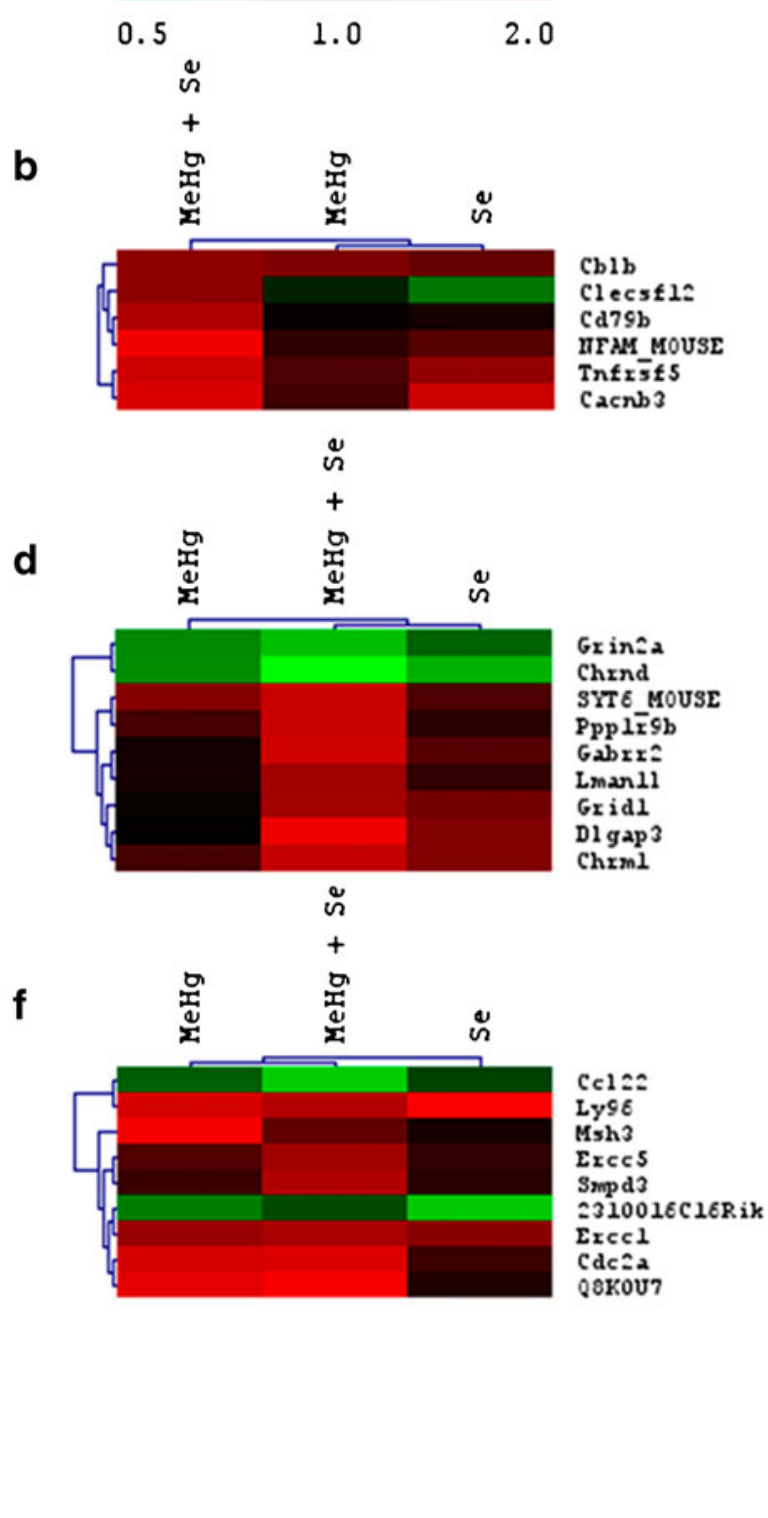

Red and green blocks respectively represent high and low expression relative to the reference RNA, while black blocks indicate equal expression. Functional clusters are as follows: a "Cell adhesion" (GOTERM_BP_ALL; MeHg+Se), b "Synapse" (SP_PIR_KEYWORDS; $\mathrm{MeHg}+\mathrm{Se}$ ), c “immune response-regulating signal transduction" (GOTERM_BP_ALL; $\mathrm{MeHg}+\mathrm{Se}$ ), d “Cell Proliferation" (GOTERM_BP_ALL; $\mathrm{MeHg}$ ), e "Response to stress" (GOTERM_BP_ALL; $\overline{\mathrm{MeHg}}$ ), f "Protein metabolism" (GOTERM_BP_ALL; Se). For each of the treatment groups, $n=4$ 
significantly differentially regulated functional clusters included "cell adhesion", "synapse", and "immune response-regulating signal transduction" under the combined exposure of $\mathrm{MeHg}$ and $\mathrm{Se}$; "cell proliferation" and "response to stress" following $\mathrm{MeHg}$ exposure; and "protein metabolism" under Se exposure.

Significant functional clusters resulting from the functional enrichment analysis under the respective treatments are given in Supplementary Tables 4, 5 and 6. These tables contain annotation types and $p$ values corresponding to each of the enriched functional clusters.

\section{Quantitative real-time PCR}

To validate the array data, 12 transcripts were selected for quantitative real-time PCR analysis. These were selected on the basis of a number of different criteria. The first group of four genes (sidekick homolog 2, $\mathrm{Sdk} 2$; regenerating islet-derived 1, Reg1; ependymin- related protein 2, Epdr2; wingless-related $\mathrm{mmtv}$ integration site 3, Wnt3) showed at least a 1.5-fold change in expression relative to the control from the microarray analysis, and featured in over-expressed functional clusters.

Sdk2 mRNA was induced by MeHg exposure, with this induction present under the combined exposure of $\mathrm{MeHg}$ and Se, but not under Se alone (Fig. 3). Wnt3 showed a significant down-regulation under $\mathrm{MeHg}$ exposure. However, under the combined exposure of $\mathrm{MeHg}$ and $\mathrm{Se}$, Wnt3 exposure was not statistically distinct from control levels. Independent of treatment, Reg 1 was up-regulated in all groups relative to control (Fig. 3).

The genes Amigo2 (adhesion molecule with ig like domain 2), Epdr2 (ependymin-related protein 2), Plp2 (proteolipid protein 2), Nptx2 (neuronal pentraxin II precursor) and F2rl2 (coagulation factor 2 (thrombin) receptor-like 2) were also selected from the array data on the basis that they showed at least 1.5 -fold change
Fig. 3 Quantitative real-time PCR analysis of the expression of six genes in murine pup brains gestationally exposed to $\mathrm{MeHg}$ and/or Se. These genes were selected on the basis of results obtained from microarray analysis. The asterisks indicates statistical significance $p<0.05$ (derived from MannWhitney test) of the different treatments when compared to the control. Non-hatched bars represent $n=4$ (qPCR samples which were also analysed via microarray) for each of the treatment groups. Hatched bars (all qPCR samples) represent $n=6$ for each of the treatment groups
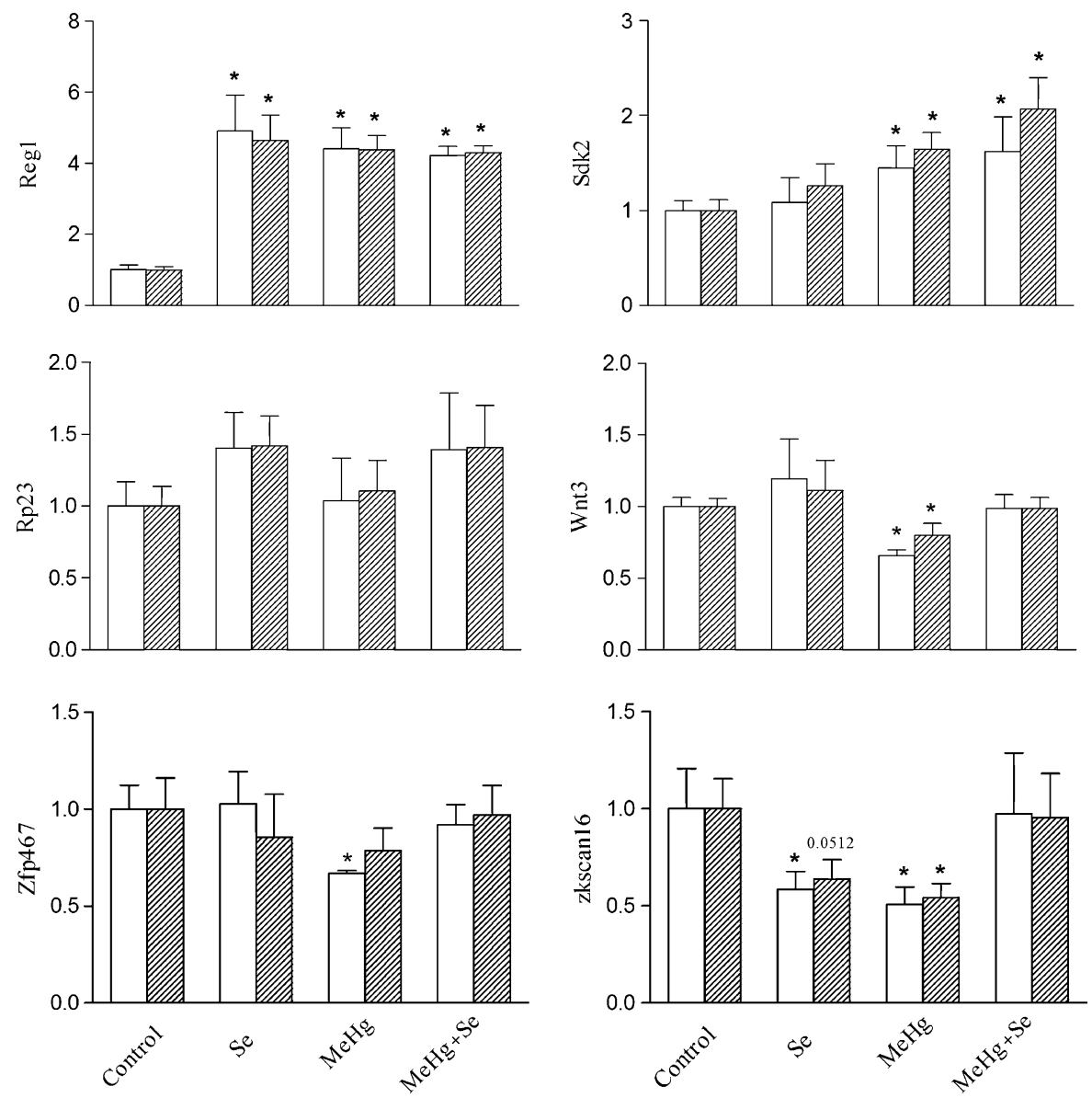
difference relative to the control. These genes exhibited no significant difference in gene expression via qPCR analysis relative to the control (Table 4).

Zinc finger protein 467 (Zfp467) and zinc finger with KRAB and SCAN domains 16 (zkscan16) were selected from the array data based on the results from a previous similar study from our laboratory (Glover et al. 2009), which described an impact of $\mathrm{MeHg}$ exposure on zinc finger transcription factors. In the current investigation Zfp467 was significantly downregulated by $\mathrm{MeHg}$ alone, but was unchanged relative to control following the dual administration of $\mathrm{Se}+$ $\mathrm{MeHg}$ (Fig. 3). It is worth noting that the significant effect of MeHg on Zfp467 expression was only noted in $\mathrm{qPCR}$ samples that were also utilised for array analysis, and that this effect disappeared once additional qPCR samples were added.

In case of Zkscan16, a significant down-regulation in Se treated pup brains and a larger reduction in gene expression level upon $\mathrm{MeHg}$ exposure was observed. However, regulation was unaltered under concurrent exposure to $\mathrm{Se}$ and $\mathrm{MeHg}$. Again, minor discrepancies between total qPCR analyses and those restricted to brain samples used for the array analysis only were noted. Such discrepancies existed only for the zinc finger genes. For all other genes assessed, the use of "array only" or "total" qPCR samples had no impact on the statistical analysis. The expression of genes encoding for Purkinje cell protein 2 (Pcp2), SPARC-like 1 (Sparcl1), myelin basic protein (Mbp) and tetraspanin 5 (Tspan5; Fig. 4) were also evaluat- ed. These genes were identified as regulated in a similar study investigating $\mathrm{MeHg}$ toxicity in rat cerebellum (Padhi et al. 2008). In the present study, RT-PCR elucidated an expression level of Sparcl1 that was significantly decreased in response to $\mathrm{MeHg}$ exposure in mice when compared to control and $\mathrm{Se}$ treatments. However, the effect was alleviated under the combined effect of $\mathrm{MeHg}+\mathrm{Se}$ (Fig. 4). The expression of $\mathrm{Mbp}$ was reduced in pup brains following $\mathrm{MeHg}$ exposure, but this effect was not significant (Fig. 4). Tspan 5 was significantly downregulated in all treatments (Fig. 4). Pcp2 showed a similar pattern of expression to Tspan5 but the difference between groups was not significant.

Of array genes selected for qPCR analysis, Reg 1, Sdk 2, RP23 (p140 gene), Syt 14 (synaptotagmin XIV) and zkscan 16, all showed some correspondence between the two methods of assessment (microarray and qPCR). These genes all exhibited a 1.5 -fold or greater difference of expression level of a similar direction (i.e. up-regulated or down-regulated) in at least one treatment relative to control for both techniques (Table 4). Genes Amigo 2, Epdr2, Plp2, F2rl2, Wnt3, Zfp467, Nptx2 failed to show any correspondence between the two methods of assessment.

\section{Discussion}

Evidence suggests that $\mathrm{Se}$ has the capacity to ameliorate $\mathrm{MeHg}$-induced effects on development in
Table 4 Summary of gene expression trends via microarray and qPCR for genes selected for qPCR analysis in murine pup brains gestationally-exposed to $\mathrm{MeHg}$ and/or Se
The arrows depict the direction of regulation in both the assessment techniques; $\uparrow$, upregulation, $\downarrow$, downregulation. Values represent fold change relative to control ${ }^{*} p<0.05$

\begin{tabular}{|c|c|c|c|c|c|c|}
\hline \multirow[b]{2}{*}{ Genes } & \multicolumn{3}{|l|}{ Array } & \multicolumn{3}{|l|}{ qPCR } \\
\hline & $\mathrm{MeHg}$ & $\mathrm{Se}$ & $\mathrm{MeHg}+\mathrm{Se}$ & $\mathrm{MeHg}$ & $\mathrm{Se}$ & $\mathrm{MeHg}+\mathrm{Se}$ \\
\hline Amigo2 & - & - & $2.3 \uparrow *$ & - & - & - \\
\hline Epdr2 & - & - & $2.4 \downarrow^{*}$ & - & - & - \\
\hline Reg1 & $1.5 \uparrow^{*}$ & $1.5 \uparrow^{*}$ & $2.5 \uparrow *$ & $4.4 \uparrow^{*}$ & $4.9 \uparrow^{*}$ & $4.2 \uparrow *$ \\
\hline Sdk2 & $1.5 \uparrow^{*}$ & - & $2.1 \uparrow^{*}$ & $1.5 \uparrow$ & - & $1.6 \uparrow *$ \\
\hline RP23 & - & - & $2.2 \uparrow *$ & - & $1.5 \uparrow$ & $1.5 \uparrow$ \\
\hline Plp2 & - & - & $2.2 \uparrow *$ & - & - & - \\
\hline F2rl2 & - & - & $2.6 \uparrow *$ & - & - & - \\
\hline Wnt3 & - & - & $2.5 \downarrow *$ & $1.4 \downarrow^{*}$ & - & - \\
\hline Syt14 & $1.6 \uparrow *$ & - & $2.3 \uparrow *$ & - & $1.5 \uparrow$ & $1.5 \uparrow$ \\
\hline Zfp467 & - & $2.2 \downarrow^{*}$ & $1.7 \downarrow *$ & $1.5 \downarrow^{*}$ & - & - \\
\hline Zkscan 16 & $1.4 \downarrow$ & - & - & $1.9 \downarrow *$ & $1.5 \downarrow^{*}$ & - \\
\hline Nptx2 & $1.7 \downarrow^{*}$ & $1.5 \downarrow^{*}$ & $2.4 \downarrow^{*}$ & - & - & - \\
\hline
\end{tabular}



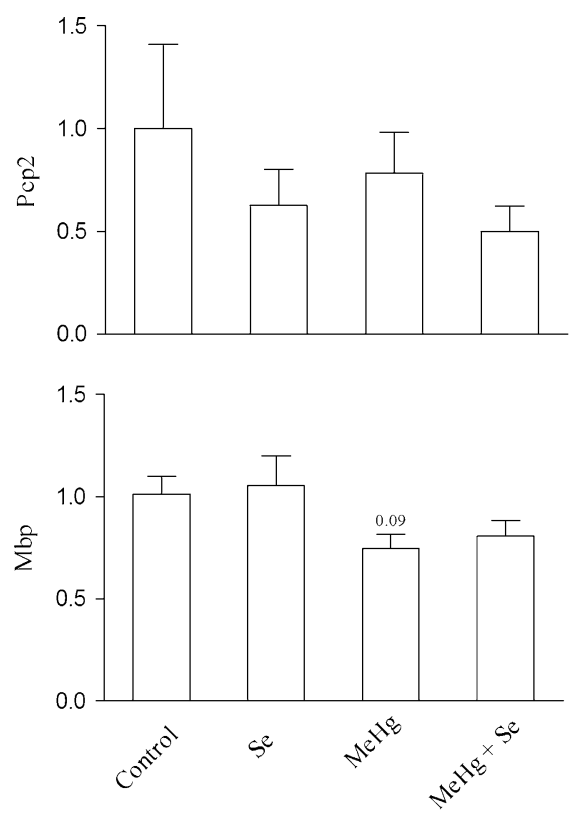

Fig. 4 Quantitative real-time PCR analysis of the expression of four genes in murine pup brains gestationally exposed to $\mathrm{MeHg}$ and/or Se. These genes were selected on the basis of results obtained from a similar study conducted on rats (Padhi et al. $2008)$. The single asterisk indicates the statistical significance $(p<0.05$ derived from Mann-Whitney test) when compared to

rodent models (Beyrouty and Chan 2006; Folven et al. 2009). Although $\mathrm{MeHg}-\mathrm{Se}$ interactions have been addressed previously, the mechanisms by which Se modulates $\mathrm{MeHg}$-induced neurotoxicity remain poorly characterised. The novel aspect of the present study lies in elucidating potential molecular mechanisms behind this protective effect in gestationally exposed mice using environmentally relevant chemical species of Se and $\mathrm{MeHg}$ and a toxicogenomic approach. The critical findings of this study were: (1) perinatal $\mathrm{MeHg}$ and $\mathrm{Se}$ (separate/concurrent) exposure induced transcriptional perturbations in murine brain; (2) $\mathrm{MeHg}$, Se and $\mathrm{MeHg}$ in combination with Se affected key functional classes of genes related to the immune system and cell adhesion; and (3) identification of significantly differentially regulated gene clusters in response to different treatments highlighted potential mechanisms of $\mathrm{Se}$ amelioration of $\mathrm{MeHg}$-induced toxicity.

The accumulation data showed that Se had no effect on whole tissue $\mathrm{Hg}$ levels. This suggests that any effect of Se was related to direct interaction with $\mathrm{MeHg}$ at a molecular level, rather than due to an effect related to lessening the bioavailability of $\mathrm{MeHg}$ for cellular uptake. However, the protocol used did
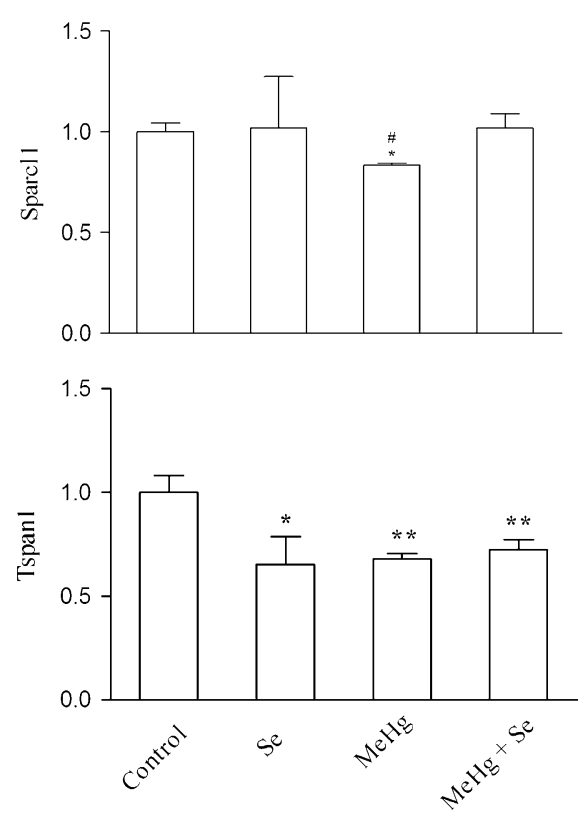

the control. The double asterisk indicates the statistical significance $(p<0.01$ derived from Mann-Whitney test) when compared to the control. The number sign indicates the statistical significance $(p<0.05$ derived from Mann-Whitney test) when compared to Se treatment; $n=6$ for each of the treatment groups

not account for changes in $\mathrm{Hg}$ distribution at a cellular level. Further studies will be needed to test this possibility. The form of Se used in the current study may have also impacted the accumulation data. Se in SeMet is relatively slowly released (Schrauzer and Surai 2009). This may have limited the formation of $\mathrm{Hg}-\mathrm{Se}$ complexes that are known to accumulate in animal tissues (Huggins et al. 2009).

Studies suggest the ratio of $\mathrm{Hg}$ to Se may be the critical factor in determining the toxicity of $\mathrm{MeHg}$ (e.g. Ralston et al. 2008). Cerebral tissue $\mathrm{Hg} / \mathrm{Se}$ molar ratios in pups subjected to the maternal $\mathrm{MeHg}$ diet in the present study were $1.2: 1$, reducing to $\sim 0.2: 1$ with Se supplementation. Under such conditions, a greater ameliorative effect of Se than that observed might have been expected. The explanation for the relatively minor impact of Se may be the chemical form of Se used. One hypothesis regarding the mechanism of Se mitigation of $\mathrm{MeHg}$ toxicity is impairment of intracellular selenocysteine cycling (Ralston et al. 2008). Selenocysteine is an amino acid that is specifically utilised to provide enzymatic activity in the active site of certain proteins (selenoenzymes; Hatfield et al. 2006). Rather than being directly recycled when these 
proteins are catabolised, the Se component of selenocysteine is normally cleaved and reattached to cysteine later in the cycle. However, by virtue of its very strong affinity for Se (Dyrssen and Wedborg 1991), MeHg scavenges the cleaved Se, with the result being impairment of selenoenzyme formation, and disruption of selenoenzyme function (e.g. antioxidant defence; Ralston et al. 2008). Supplementation of Se using a poorly labile form (SeMet) in the current study, may have failed to sufficiently replace Se into the cellular selenocysteine cycle, and thus may have had limited capacity to offset $\mathrm{MeHg}$ effects. It has been shown, for example, that SeMet may become trapped in multiple cycles of protein synthesis as methionine equivalent, before becoming available for selenocysteine synthesis (Ralston and Raymond 2010). However, in spite of the possible effects on selenoprotein synthesis impact on genes encoding, selenoproteins were not detected using microarray in the present study. Further studies specifically examining this important group of proteins may better discern the mechanism by which $\mathrm{MeHg}$ and Se interact in murine brain.

Microarray analysis provided novel insight regarding the molecular mechanisms behind Se amelioration of $\mathrm{MeHg}$ neurotoxicity. Although the hierarchical clustering on experimental groups revealed discrimination of treatments based on gene expression pattern, microarrays were unable to completely discriminate between individual samples assigned to different treatment groups. Consistent with other studies (Glover et al. 2009; Padhi et al. 2008), only a small effect of $\mathrm{MeHg}$ on brain gene expression was noted, suggesting that gene expression in brain is, compared with many other tissues, remarkably stable. The combination of a relatively low dose and generally low-fold changes results in global gene expression profiles, that are meaningful when averaged between biological replicates, but alone do not allow individual sample discrimination. The use of higher doses of $\mathrm{MeHg}$ (particularly in animals exhibiting Se depletion) would likely have generated greater effects and also more complete hierarchical clustering of samples according to treatments. However, the effects observed at higher (and unrealistic) doses of $\mathrm{MeHg}$ may very well be different from those that occur at lower doses.

In the current investigation, a complete validation of results between the array and qPCR was lacking. There could have been several reasons for the disagree- ment between results from the two methods. Most genes have several transcripts and it is possible that PCR amplicons did not always correspond to the region of probe binding ( $3^{\prime}$ bias). In the current study, if the regulation of genes in both the techniques were in the same direction, it was considered a good correspondence. The basis for this approach was that microarray is a semiquantitative technique, while qPCR is a more sensitive methodology (Bustin 2004); hence, it is difficult to attain similar fold changes. The reduced sensitivity of array technology may stem in part from the lasers used to scan the arrays, which had a threshold limiting the accurate measurement of gene regulation. There are no such limits with regard to qPCR, where the intensity of the fluorescence is detected by the real-time PCR machine. Spots on the array can also be saturated which could confound interpretation of microarray data. The use of different data normalisation procedures in both the techniques could also contribute towards the differences observed in gene expression values.

To explore the possibility that the relatively poor correspondence between qPCR and array data was related to biological variation (i.e. that use of distinct samples was responsible for the differences observed), qPCR data was analysed two ways. One assessment utilised the data derived only from those brains also used for array analysis, and the other included all samples. In general, the statistical analysis using these two qPCR approaches was identical, indicating that the lack of correlation was not related to inherent differences in the gene expression of individual pup brains. However, results did indicate that the response of zincfinger genes to $\mathrm{MeHg}$ exposure may exhibit significant inter-individual variability.

Functional annotation enrichment analysis provided potential links between $\mathrm{MeHg}$ and $\mathrm{Se}$ exposure and identified potentially important cellular pathways of $\mathrm{MeHg}$ toxicity and affected genes associated with cell adhesion, immune system, stress response, and neuron communication. The effect of $\mathrm{MeHg}$ on the immune system has been explored in both in vitro and in vivo studies (Graevskaya et al. 2003; Omara et al. 1997; Thuvander et al. 1996). A study performed on $\mathrm{balb} / \mathrm{c}$ mice indicated that chronic exposure to $\mathrm{MeHg}$ in dams resulted in transfer of $\mathrm{MeHg}$ to pups which impacted thymocyte development and stimulated lymphocyte activities (Thuvander et al. 1996). In the current study, gene clusters related to immune system were impacted by $\mathrm{MeHg}$ exposure. 
Conversely, Se is important for the optimal functioning of the immune system and is known to regulate the expression of pro-inflammatory genes in immune cells (Vunta et al. 2008). The appearance of several functional clusters related to the immune system under the combined exposure of $\mathrm{MeHg}$ and Se suggests an influence of Se on the regulation of genes involved in maintaining the immune defence of the body, possibly in order to balance the immunological effects of MeHg.

Similarly, the combined effect of $\mathrm{MeHg}$ and $\mathrm{Se}$ exposure highlighted an impact of Se on genes related to cell adhesion. Neural cell adhesion molecules (NCAMs) are cell surface glycoproteins that regulate cell-cell recognition and adhesion to guide neuronal migration, elongation and synaptogenesis (Regan and Fox 1995). NCAMs have disulfide-bonded immunoglobulin-like segments in their extracellular domain. As such they are a likely target for $\mathrm{MeHg}$ toxicity (Sass et al. 2001), and thus a putative target for Se amelioration. A study conducted with corticoid-dependent asthmatics demonstrated that Se supplementation affected the expression of adhesion molecules, which play an important role in inflammation (Jahnova et al. 2002). The enrichment of functional clusters related to cell adhesion could be a Se-mediated mechanism to offset or repair the damage caused by MeHg. Further studies are warranted to confirm such effects since extrapolating impacts from microarray expression data, especially from murine developing brain, is complex.

Effects on both the immune system and cell adhesion were most prominent under dual $\mathrm{Se}$ and $\mathrm{MeHg}$ exposure. Functional clusters "calcium binding", "synapse", "cytoskeleton", “cell differentiation", “cell proliferation", "transcription regulation", and "metal binding" were also enriched under $\mathrm{MeHg}$ and Se coexposure, reflecting the wide variety of genes influenced by co-administration. It is also interesting to note that the concomitant exposure regime induced the greatest overall response in gene expression change. The reason for this is unclear. A recent study by Shimada et al. (2010) found that the concurrent exposure of $\mathrm{MeHg}$ with polychlorinated biphenyls also induced a much larger number of significant changes in gene expression than exposure to the individual components alone. The gene expression response to the concurrent exposure of $\mathrm{MeHg}$ and $\mathrm{Se}$ in the current investigation may reflect effects related to the strong affinity between $\mathrm{MeHg}$ and $\mathrm{Se}$ that would not be apparent when each is dosed independently.

The comparative toxicogenomic database was probed using DAVID in order to examine the relative gene expression profiles generated by exposures to toxic metals and metalloids. A functional annotation enrichment analysis was performed on genes identified to be regulated in mouse (Mus musculus) for each of four metals (MeHg, zinc, arsenic and cadmium). Functional clusters of genes related to morphogenesis/ development were identified as being regulated following the exposure of each of the four metals, the only cluster found to be common to all. While other clusters overlapped between two metals, profiles were largely distinct. This is not surprising given distinct mechanisms of toxic action, and the significant variation in experimental protocols used to generate the data.

The genes Wnt3 and Sparcl1 showed Se-mediated affects on MeHg-induced changes in gene expression. Wnt3 is expressed during the development of the cerebellum and Sparcll is involved in cell migration (Salinas et al. 1994; Gongidi et al. 2004). Perturbations in these genes could hinder the development of the brain. Hence, Se may be considered a therapeutic agent in this scenario, owing to its properties in reversing $\mathrm{MeHg}$-induced changes in these critical genes. The expression of $\mathrm{Sdk} 2$ remained unaltered by $\mathrm{Se}$ exposure, but was up-regulated in the $\mathrm{MeHg}$ treatments. $\mathrm{Sdk} 2$ is a mediator of homophilic adhesion and has an important role in guiding neuronal migration during development (Hayashi et al. 2005; Yamagata et al. 2002). The impairment of Sdk2 expression levels could have an obvious and important role in mediating $\mathrm{MeHg}$ toxicity. As such Sdk2 could be a potential candidate as a biomarker of $\mathrm{MeHg}$ exposure and/or effect. Studies on Sdk2 expression in human tissues accessible via biopsy may be warranted.

The genes Reg 1 and Tspan5 involved in differentiation and proliferation (Namikawa et al. 2005) and neuronal differentiation (Juenger et al. 2005), respectively, were affected by all treatments $\mathrm{Se}, \mathrm{MeHg}$, and $\mathrm{MeHg}+\mathrm{Se}$ ). In the current study, the genes Mbp, Tspan5, and Sparcll showed changes comparable to those obtained in response to $\mathrm{MeHg}$ exposure in a similar study performed on rats (Padhi et al. 2008), supporting the findings of the present study. Expression profiles of these genes in response to $\mathrm{MeHg}$ appear to be conserved between both rats and mice 
allowing interspecies extrapolation. Future studies examining the mechanisms of $\mathrm{MeHg}$ could focus on understanding the roles of these genes in mediating toxicity.

Another interesting feature prevalent in the gene expression data was the differential regulation of genes encoding zfp467 and zkscan16. The interactions between zinc finger proteins and $\mathrm{MeHg}$ toxicity have been largely overlooked in the literature. However, previous microarray data revealed a distinct effect of $\mathrm{MeHg}$ toxicity on the expression of mRNA encoding zinc finger proteins (Glover et al. 2009). Both Zfp467 and zkscan16 code for zinc finger proteins that are important for RNA packaging, DNA recognition, transcriptional activation, regulation of apoptosis, protein folding and assembly and lipid binding (Laity et al. 2001). Se alleviated the down-regulation of Zfp467 under $\mathrm{MeHg}$ exposure, returning expression back to control levels indicating its potential to counteract $\mathrm{MeHg}$ induced damage. This suggests that these transcripts could be key targets for Se-amelioration of $\mathrm{MeHg}$ induced toxicity.

A controversial finding of the present study was the lack of markers of oxidative stress identified as being differentially expressed on $\mathrm{MeHg}$ exposure. While this finding is consistent with previous microarray data from this laboratory (Glover et al. 2009), it is contrary to the established dogma regarding a key mechanism of $\mathrm{MeHg}$ toxicity. For example, Kaur et al. (2009) found an effect of SeMet in reducing $\mathrm{MeHg}$-induced ROS production in neural cell lines. Similarly, an in vivo study found that administration of Se resulted in restoration of MeHg-induced depletion of antioxidant enzymatic activities (Agarwal and Behari 2007). There are several possible reasons for this difference between studies. The present study sampled brains at a single time-point, which may have precluded detection of oxidative stress or ameliorating pathways. The exposure regime employed in this study (sub-chronic exposure throughout gestation), may have allowed the gradual development of antioxidant defence mechanisms, which would not necessarily be reflected in altered brain gene expression levels at the chosen sampling time. In this context, it should be noted that observed effects on neurological development in these mice were limited (Folven et al. 2009). In contrast, the acute exposure regimes of many previous studies would be more likely to overwhelm antioxidant mechanisms, and induce significant changes in molecular pathways related to this phenomenon. This suggests that chronic perinatal exposure through a natural route may result in a significantly different toxicological profile than acute exposure studies. Furthermore, since $\mathrm{MeHg}$ found in seafood is bound to cysteine (Harris et al. 2003), MeHgCys was the chemical species of mercury chosen for the present study. This is in contrast to most laboratory studies where $\mathrm{MeHgCl}$ is the chemical species used. In vivo studies have shown that $\mathrm{MeHgCl}$ and $\mathrm{MeHgCys}$ differ in their toxicological impacts (Glover et al. 2009; Berntssen et al. 2004) and this effect may also account for differences between the present study and others with respect to the impact of antioxidant stress.

\section{Conclusion}

There are several hypotheses suggested in the literature regarding $\mathrm{MeHg}$ and $\mathrm{Se}$ interaction but there remains uncertainty regarding the mechanism by which Se may protect against $\mathrm{MeHg}$-induced toxicity. The results from the current investigation demonstrated the utility of toxicogenomics for identifying novel processes that may be responsible for Se-mediated modulation of $\mathrm{MeHg}$ toxicity. In the present study, Se affected specific subsets of genes impacted by $\mathrm{MeHg}$ exposure, and had a role in modifying the transcription of key functional classes of genes when exposure occurred with $\mathrm{MeHg}$. The use of a sub-chronic exposure regime, during the sensitive stages of brain development, using environmentally relevant $\mathrm{Se}$ and $\mathrm{MeHg}$ exposure species offers unique insight compared to common laboratory protocols. Overall, the results from the present investigation contribute novel information facilitating the identification of molecular mechanisms of toxicity, which may prove valuable for extrapolation to human exposure to $\mathrm{MeHg}$ via seafood.

\section{Funding}

This work was supported by the Research Council of Norway [NFR 173389] and the EU FRP6 integrated project "Aquamax" [016249-2]. 
Acknowledgements The authors would like to thank Aase Heltveit for technical assistance and animal husbandry; Berit Solli for mercury analysis; Dr. Matthew Arno, King's College London Genomics Centre for facilitating the microarray work; Dr. Parvinder Kaur and Prof. Tore Syversen for fruitful scientific discussion. This study and the experimental facilities at NIFES were approved by the Norwegian Animal Research Authority.

Open Access This article is distributed under the terms of the Creative Commons Attribution Noncommercial License which permits any noncommercial use, distribution, and reproduction in any medium, provided the original author(s) and source are credited.

\section{References}

Agarwal R, Behari JR. Role of selenium in mercury intoxication in mice. Ind Health. 2007;45:388-95.

Aschner M, Syversen T. Methylmercury-recent advances in the understanding of its neurotoxicity. Ther Drug Monit. 2005;27:278-83.

Berntssen MHG, Hylland K, Lundebye AK, Julshamn K. Higher faecal excretion and lower tissue accumulation of mercury in wistar rats from contaminated fish than from methylmercury chloride added to fish. Food Chem Toxicol. 2004;42:1359-66.

Beyrouty P, Chan HM. Co-consumption of selenium and vitamin $\mathrm{E}$ altered the reproductive and developmental toxicity of methylmercury in rats. Neurotoxicol Teratol. 2006;28:49-58.

Bridges CC, Zalups RK. Molecular and ionic mimicry and the transport of toxic metals. Toxicol Appl Pharmacol. 2005;204:274-308.

Bustin SA. A-Z of quantitative PCR. La Jolla, CA, USA: International University Line; 2004.

Carvalho CML, Chew E-H, Hashemy SI, Lu J, Holmgren A. Inhibition of the human thioredoxin system: a molecular mechanism of mercury toxicity. J Biol Chem. 2008;283:11913-23.

Cabanero AI, Madrid Y, Camara C. Selenium and mercury bioaccessibility in fish samples: an in vitro digestion method. Anal Chim Acta. 2004;526:51-61.

Choi AL, Budtz-Jorgensen E, Jorgensen PJ, Steuerwald U, Debes F, Weihe P, et al. Selenium as a potential protective factor against mercury developmental neurotoxicity. Environ Res. 2008; 107:45-52.

Debes F, Budtz-Jorgensen E, Weihe P, White RF, Grandjean P. Impact of prenatal methylmercury exposure on neurobehavioral function at age 14 years. Neurotoxicol Teratol. 2006;28:363-75.

Dennis Jr G, Sherman BT, Hosack DA, Yang J, Gao W, Lane $\mathrm{HC}$, et al. DAVID: database for annotation, visualization, and integrated discovery. Genome Biol. 2003;4:3.

Dyrssen D, Wedborg M. The sulfur-mercury(II) system in natural waters. Water Air Soil Pollut. 1991;56:507-19.

Folven KI, Glover CN, Malde MK, Lundebye AK. Does selenium modify neurobehavioural impacts of developmental methyl- mercury exposure in mice? Environ Toxicol Pharmacol. 2009;28:111-9.

Fox TE, Van den Heuvel EGHM, Atherton CA, Dainty JR, Lewis DJ, Langford NJ, et al. Bioavailability of selenium from fish, yeast and selenate: a comparative study in humans using stable isotopes. Eur J Clin Nutr. 2004;58:343-9.

Fredriksson A, Gardlund AT, Bergman K, Oskarsson A, Ohlin B, Danielsson B, et al. Effects of maternal dietary supplementation with selenite on the postnatal development of rat offspring exposed to methyl mercury in utero. Pharmacol Toxicol. 1993;72:377-82.

Glover CN, Zheng D, Jayashankar S, Sales GD, Hogstrand C, Lundebye AK. Methylmercury speciation influences brain gene expression and behaviour in gestationally exposed mice pups. Toxicol Sci. 2009;110:389-400.

Gongidi V, Ring C, Moody M, Brekken R, Sage EH, Rakic P, et al. SPARC-like 1 regulates the terminal phase of radial glia-guided migration in the cerebral cortex. Neuron. 2004;41:57-69.

Graevskaya EE, Yasutake A, Aramaki R, Rubin AB. Effect of methylmercury on the rat mast cell degranulation. J Physiq IV. 2003;107:565-8.

Harris HH, Pickering IJ, George GN. The chemical form of mercury in fish. Science. 2003;301:1203-3.

Hatfield DL, Carlson BA, Xu XM, Mix H, Gladyshev VN. Selenocysteine incorporation machinery and the role of selenoproteins in development and health. Progr Nucl Acid Res Mol Biol. 2006;81:97-142.

Hayashi K, Kaufman L, Ross MD, Klotman PE. Definition of the critical domains required for homophilic targeting of mouse sidekick molecules. FASEB J. 2005;19:614-6.

Huang LS, Cox C, Myers GJ, Davidson PW, Cernichiari E, Shamlaye CF, et al. Exploring nonlinear association between prenatal methylmercury exposure from fish consumption and child development: evaluation of the Seychelles Child Development Study nine-year data using semiparametric additive models. Environ Res. 2005;97:100-8.

Huggins F, Raverty SA, Nielsen OS, Sharp N, Robertson JD, Ralston NVC. An XAFS investigation of mercury and selenium in beluga whale tissues. Environ Bioindicat. 2009;4:291-302.

Jahnova E, Horvathova M, Gazdik F, Weissova S. Effects of selenium supplementation on expression of adhesion molecules in corticoid-dependent asthmatics. Bratisl Med J. 2002;103:12-6.

Juenger CH, Holst MI, Duffe K, Jankowski J, Baader SL. Tetraspanin-5 (Tm4sf9) mRNA expression parallels neuronal maturation in the cerebellum of normal and L7En-2 transgenic mice. J Comp Neurol. 2005;483:31828.

Julshamn K, Andersen A, Ringdal O, Morkore J. Trace-elements intake in the Faroe Islands. 1. Element levels in edible parts of pilot whales (Globicephalus meleanus). Sci Total Environ. 1987;65:53-62.

Julshamn K, Måge A, Norli HS, Grobecker KH, Jorhem L, Fecher P. Determination of arsenic, cadmium, mercury and lead by ICP-MS in foods after pressure digestion: NMKL Collaborative study. J AOAC Int. 2007;90:844-56. 
Kaur P, Evje L, Aschner M, Syversen T. The in vitro effects of selenomethionine on methylmercury-induced neurotoxicity. Toxicol in Vitro. 2009;23:378-85.

Kohrle J, Jakob F, Contempre B, Dumont JE. Selenium, the thyroid, and the endocrine system. Endocr Rev. 2005;26:944-84.

Laity JH, Lee BM, Wright PE. Zinc finger proteins: new insights into structural and functional diversity. Curr Opin Struct Biol. 2001;11:39-46.

Litov RE, Combs GF. Selenium in pediatric nutrition. Pediatrics. 1991;87:339-57.

Myers GJ, Davidson PW, Cox C, Shamlaye CF, Palumbo D, Cernichiari E, et al. Prenatal methylmercury exposure from ocean fish consumption in the Seychelles Child Development Study. Lancet. 2003;361:1686-92.

Myers GJ, Thurston SW, Pearson AT, Davidson PW, Cox C, Shamlaye CF, et al. Postnatal exposure to methyl mercury from fish consumption: a review and new data from the Seychelles Child Development Study. Neurotoxicology. 2009;30:338-49.

Namikawa K, Fukushima M, Murakami K, Suzuki A, Takasawa $\mathrm{S}$, Okamoto H, et al. Expression of Reg/PAP family members during motor nerve regeneration in rat. Biochem Biophys Res Commun. 2005;332:126-34.

Omara FO, Brochu C, Flipo D, Denizeau F, Fournier M. Immunotoxicity of environmentally relevant mixtures of polychlorinated aromatic hydrocarbons with methyl mercury on rat lymphocytes in vitro. Environ Toxicol Chem. 1997;16:576-81.

Ørnsrud R, Lorentzen M. Bioavailability of selenium from raw or cured selenomethionine-enriched fillets of Atlantic salmon (Salmo salar) assessed in selenium deficient rats. Br J Nutr. 2002;87:13-20.

Padhi BK, Pelletier G, Williams A, Berndt-Weis L, Yauk C, Bowers WJ, et al. Gene expression profiling in rat cerebellum following in utero and lactational exposure to mixtures of methylmercury, polychlorinated biphenyls and organochlorine pesticides. Toxicol Lett. 2008;176:93-103.

Ralston NVC, Ralston CR, Blackwell III JL, Raymond LJ. Dietary and tissue selenium in relation to methylmercury toxicity. Neurotoxicology. 2008;29:802-11.

Ralston NVC, Raymond LJ. Dietary selenium's protective effects against methylmercury toxicity. Toxicology. 2010. doi:10.1016/j.tox.2010.06.004.

Reed MN, Banna KM, Donlin WD, Newland C. Effects of gestational exposure to methylmercury and dietary selenium on reinforcement efficacy in adulthood. Neurotoxicol Teratol. 2008;30:29-37.
Regan CM, Fox GB. Polysialylation as a regulator of neural plasticity in rodent learning and aging. Neurochem Res. 1995;20:593-8.

Robinson J, Shroff J. Observations on the levels of total mercury $(\mathrm{Hg})$ an selenium $(\mathrm{Se})$ in species common to the artisanal fisheries of Seychelles. Seychelles Med Dental J. 2004;7:56-60.

Saeed AI, Sharov V, White J, Li J, Liang W, Bhagabati N, et al. TM4: a free, open-source system for microarray data management and analysis. Biotechniques. 2003;34:374-8.

Salinas PC, Fletcher C, Copeland NG, Jenkins NA, Nusse R. Maintenance of Wnt-3 expression in Purkinje cells of the mouse cerebellum depends on interactions with granule cells. Development. 1994;120:1277-86.

Sass JB, Haselow DT, Silbergeld EK. Methylmercury-induced decrement in neuronal migration may involve cytokinedependent mechanisms: a novel method to assess neuronal movement in vitro. Toxicol Sci. 2001;63:74-81.

Schrauzer GN, Surai PF. Selenium in human and animal nutrition: resolved and unresolved issues. Crit Rev Biotechnol. 2009;29:2-9.

Seppanen K, Soininen P, Salonen JT, Lotjonen S, Laatikainen R. Does mercury promote lipid peroxidation? An in vitro study concerning mercury, copper, and iron in peroxidation of low-density lipoprotein. Biol Trace Elem Res. 2004;101:117-32.

Shimada M, Kameo S, Sugawara N, Yaginuma-Sakurai K, Kurokawa N, Mizukami-Murata S, et al. Gene expression profiles in the brain of the neonate mouse perinatally exposed to methylmercury and/or polychlorinated biphenyls. Arch Toxicol. 2010;84:271-86.

Thuvander A, Sundberg J, Oskarsson A. Immunomodulating effects after perinatal exposure to methylmercury in mice. Toxicol. 1996;114:163-75.

Vandesompele J, De Preter K, Pattyn F, Poppe B, Van Roy $\mathrm{N}$, De Paepe A, et al. Accurate normalization of realtime quantitative RT-PCR data by geometric averaging of multiple internal control genes. Genome Biol. 2002;3:34.

Vunta H, Belda BJ, Arner RJ, Reddy CC, Heuvel JPV, Prabhu KS. Selenium attenuates pro-inflammatory gene expression in macrophages. Mol Nutr Food Res. 2008;52:131623.

Watanabe C. Modification of mercury toxicity by selenium: practical importance? Tohoku J Exp Med. 2002;196:71-7.

Yamagata M, Weiner JA, Sanes JR. Sidekicks: synaptic adhesion molecules that promote lamina-specific connectivity in the retina. Cell. 2002;110:649-60. 